\title{
Association Between the Deletion Allele of Ins/Del Polymorphism (Rs145204276) in the Promoter Region of GAS5 with the Risk of Atherosclerosis
}

\author{
Zheng Shen ${ }^{a, b} \quad$ Qiang She ${ }^{a}$ \\ aDepartment of Cardiology, the Second Affiliated Hospital of Chongqing Medical University, \\ Chongqing, 'Department of Cardiology, the Affiliated Hospital of Guizhou Medical University, Guiyang, \\ China
}

\author{
Key Words \\ Atherosclerosis • GAS5 • Rs145204276 • MiR-21 • PDCD4
}

\begin{abstract}
Background/Aims: LncRNA is a growth arrest-specific transcript 5 (GAS5) with tumor suppressor activities in some cancers, but its role in atherosclerosis is unclear. Methods: Bioinformatics algorithm analysis was utilized to search the target of GAS5 and miR-21, followed by luciferase assay to confirm these targets. Real-time PCR and western-blot were utilized to verify the connection among GAS5, miR-21 and Programmed cell death 4 (PDCD4). MTT assay and flow cytometry analysis were performed to explore the mechanism of GAS5 in the regulation of atherosclerosis. Results: GAS5 directly targets miR-21 and functions as a competing endogenous RNA to suppress miR-21 expression. We also observed that rs 145204276 polymorphism, including INS/INS and DEL/DEL, on GAS5 promoter increased transcription activity of GAS5, but the presence of rs 145204276 DEL/DEL allele significantly promoted the transcription of GAS5 promoter compared with rs145204276 INS/INS allele. $P D C D 4$ was predicted as a direct target gene of miR-21 with a binding site on PDCD4 $3^{\prime} U T R$. It was further confirmed by luciferase assay that miR-21 significantly reduced the luciferase activity of wild-type PDCD4 3'UTR but not that of mutant PDCD4 3'UTR. In addition, high glucose significantly inhibited the growth rate of EC genotyped as DEL/DEL or INS/ INS, and apparently promoted the apoptotic rate of either DEL/DEL or INS/INS genotype ECs. Furthermore, the effect of high glucose was stronger in the INS/INS group, while the expression of GAS5 was dramatically upregulated with the presence of GAS5 DEL/DEL, while GAS5 positively regulated PDCD4 expression via inhibiting miR-21 expression. GAS5 siRNA and miR-21 mimics significantly decreased GAS5 and PDCD4 expressions, and the inhibitory effects of GAS5 siRNA or miR-21 mimics on GAS5 and PDCD4 expressions in the INS/INS group was stronger. Moreover, GAS5 siRNA and miR-21 mimics remarkably triggered cells
\end{abstract}

\begin{tabular}{ll}
\hline Qiang She & Department of Cardiology, The Second Affiliated Hospital of Chongqing Medical University \\
& Linjiang Rd, Chongqing, 400010 (China) \\
& E-Mail ncrnaheart@yeah.net
\end{tabular}




\section{Cellular Physiology Cell Physiol Biochem 2018;49:1431-1443

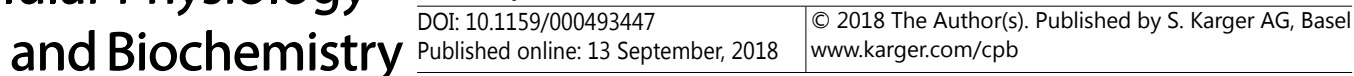 \\ Shen et al.: Rs145204276 was Associated with Atherosclerosis}

proliferation and suppressed cell apoptosis, and the inhibition effects of GAS5 siRNA or miR21 mimics on either cell viability and apoptosis in the INS/INS group was stronger. In this study, we enrolled 1,306 subjects with or without atherosclerosis and found that the INS/DEL or DEL/DEL genotypes significantly decreased the risk of atherosclerosis compared with the ins/ins genotype (adjusted odds ratio: 0.74 and 0.40, respectively). Conclusion: In summary, rs 145204276 was associated with the risk of atherosclerosis by affecting the proliferation and apoptosis of endothelial cells via regulating the GAS5/miR-21/PDCD4 signaling pathway.

\section{Introduction}

Atherosclerosis, originally known as carotid stenosis or coronary artery disease (CAD), is a main contributor to stroke and myocardial infarction (MI), which accounted for over $50 \%$ of deaths in the world and is among the top contributors to disability and mortality $[1,2]$. A critical process for the development of atherosclerosis is endothelial cell (EC) apoptosis [3]. The endothelium may become unable to during inflammation, immunity and lipid homeostasis due to the apoptosis of endothelial cells [4]. In addition, the damage to endothelial cells can destroy the barrier function, impair the integrity of endothelium and enhance lipid deposition, eventually resulting in atherogenesis [5].

Programmed cell death 4 (PDCD4) was first identified as a tumor inhibitor and its expression is significantly increased by apoptosis [6]. In addition to tumor cells, cardiac muscle and endothelial cells also express PDCD4 [7] which is known to play a critical function in cardiovascular cell biology by inhibiting the expression of contractile genes in vascular smooth muscle cells and by triggering apoptosis and suppressing proliferation of many types of cardiovascular cells, such as fibroblasts, cardiac myocytes and vascular smooth muscle cells (endothelial cells) [7-10]. Low PDCD4 level was related to lower proliferation of ECs [11].

It has been shown that up to $98 \%$ of the human genome encodes for noncoding transcripts and it was postulated that variations in organism complexity may be caused by the great variations in noncoding transcripts between lower and higher organisms [12]. A lot of such noncoding transcripts are processed to produce small noncoding RNAs including IncRNAs or miRNAs. As a family of small (18-22 nucleotide, nt) and endogenous noncoding RNA molecules, miRNAs target specific messenger RNAs and hence play a negative regulatory role in gene expression by triggering the translational repression or degradation of their target genes [13, 14].In contrary, lncRNAs belong to a big family of transcribed RNA molecules (over $200 \mathrm{nt}$ ) with little potential to code proteins $[15,16]$. Recent studies have focused on the effects of IncRNAs in atherosclerosis [17]. It was shown that antisense noncoding RNA in the INK4 locus (ANRIL) and lncRNA-H19 are associated with the risk of CAD and atherosclerosis [18]. It is also revealed that long intergenic noncoding RNA p21 (lincRNA-p21) is related to atherosclerosis via affecting the proliferation and apoptosis of endothelial cells [19]. Recently, a study has demonstrated that the expression of miR-21 was markedly up-regulated in atherosclerotic plaques [20]. Furthermore, miR-21 had a negative regulatory role in lipid buildup through TLR4-NF- $\kappa B$ pathway in LPS-activated macrophages, indicating the involvement of miR-21 in atherosclerosis [21].

The gene expression and function could be significantly impacted by single nucleotide polymorphisms (SNP). Growing data have revealed that SNPs in some lncRNAs are associated with chemotherapy response and tumorigenesis [22]. For example, the rs145204276 located in the promoter region of GAS5 has been reported to be an endogenous competing RNA of miR-21[23-25]. Also, PDCD4 is believed to play a critical function in the pathogenesis of atherosclerosis by modulating the apoptosis of vascular endothelial cells [26, 27], while our in-silicon analysis also found that miR-21 virtually targeted PDCD4. In this study, we aimed to explore the role of GAS5, miR-21, and its target genePDCD4, in the control of apoptosis of endothelial cells. We also investigated the influence of rs145204276 on the risk of atherosclerosis in a Chinese population. 


\section{Cellular Physiology Cell Physiol Biochem 2018;49:1431-1443 \begin{tabular}{l|l|l} 
and Biochemistry & Dublished online: 13 September, 2018 & $\begin{array}{l}\text { (c) } 2018 \text { The Author(s). Published by S. Karger AG, Basel } \\
\text { www.karger.com/cpb }\end{array}$
\end{tabular}}

\section{Materials and Methods}

\section{Collection of umbilical vein}

A total of 1306 subjects were enrolled for our research, which consists of 681 patients diagnosed with atherosclerosis and 624 subjects without atherosclerosis. The demographic and clinicopathological characteristics of the participants, such as gender, age, hypertension, diabetes mellitus, hypercholesterolemia, and smoking are displayed in Table 1. The Ethics Committee of our institute approved the protocol of this study, which was conducted following the Declaration of Helsinki. The umbilical cord vein samples were collected from all subjects after spontaneous delivery, and stored at $-80^{\circ} \mathrm{C}$ for further analysis.

\section{Endothelial cell isolation and culture}

The tissue samples were maintained in Hanks' balanced salt solution. Subsequently, a solution containing $4 \mathrm{mg} / \mathrm{mL}$ dispase (Hyclone; GE Healthcare Life Sciences, Logan, UT) and $3 \mathrm{mg} / \mathrm{mL}$ collagenase type I (Hyclone; GE Healthcare Life Sciences, Logan, UT) was utilized to digest and mince the tissue samples at $37^{\circ} \mathrm{C}$ for $60 \mathrm{~min}$. A 70-mm strainer (Falcon; Corning Life Sciences, Tewksbury, MA) was utilized to pass the cells to yield single cell suspensions. An alpha modification of Eagle medium (GIBCO/Invitrogen, Carlsbad, CA) containing 10\% fetal bovine serum (Sigma-Aldrich, St Louis, MO), $100 \mathrm{mg} / \mathrm{mL}$ streptomycin and 100 $\mathrm{U} / \mathrm{mL}$ penicillin (Sigma-Aldrich, St Louis, MO) and $2 \mathrm{mmol} / \mathrm{L}$ glutamine (Sigma-Aldrich, St Louis, MO) was utilized to culture the cells in 48 -well plates at $5 \% \mathrm{CO}_{2}$ and $37^{\circ} \mathrm{C}$. The growth medium was changed every 2 days till the cells were cloned, which were then transferred into a new dish. After the confluence reached $80 \%$, the experiments were done using passage 2 Cells.

\section{Genotyping}

A Gentra DNA Isolation Kit (Thermo Fisher Scientific, Waltham, MA) was utilized to isolate the DNA from blood samples following the manufacturer's instruction. SNP rs145204276 was genotyped for all subjects with atherosclerosis. A BigDye3 terminator cycle sequencing kit (PE Applied Biosystems, Thermo Fisher Scientific, Waltham, MA) was utilized to analyze both forward and reverse sequencing based on the manufacturer's recommendation. An ABI PRISM 3100 Genomic Analyser (PE Applied Biosystems, Thermo Fisher Scientific, Waltham, MA) was utilized to perform the genotyping analysis.

\section{MicroRNA and IncRNA RNA isolation and real-time PCR}

Trizol reagent (Invitrogen, Thermo Fisher Scientific, Waltham, MA) was utilized to extract total RNA from endothelial cells and tissue samples in accordance with the supplier's guideline. RNA was quantified based on its OD260 value using an Eppendorf Biophotometer (Hamburg, Germany). The extracted RNA was resuspended in $50 \mu \mathrm{L}$ RNase free water and then stored at $-80^{\circ} \mathrm{C}$. A first strand cDNA synthesis kit (TOYOBO, Japan) was utilized to reversely transcribe $2 \mu \mathrm{g}$ total RNA into cDNA using oligo (dT) primers according to the manufacturer's protocol. The synthesized cDNA was then diluted by $1: 20$ and kept at $-20^{\circ} \mathrm{C}$. GAPDH served as the internal control gene during the reverse transcription. Subsequently, a Chromo4 Real-Time Detection System (MJ Research, Cambridge, MA) in conjunction with a SYBR Green qPCR kit (Finnzymes, Finland) was utilized to conduct qPCR in a $20 \mu \mathrm{L}$ volume containing $1 \mu \mathrm{L}$ cDNA, $1 \mu \mathrm{L}$ primers, $1 \mu \mathrm{L}$ sterile deionized water and $10 \mu \mathrm{L}$ SYBR Green I mixture. The qPCR reaction was run at $95^{\circ} \mathrm{C}$ for $90 \mathrm{~s}$, followed by 45 cycles of $95^{\circ} \mathrm{C}$ for $15 \mathrm{~s}, 60^{\circ} \mathrm{C}$ for $20 \mathrm{~s}$ and $72^{\circ} \mathrm{C}$ for $15 \mathrm{~s}$. All reactions were repeated in triplicate and the $2^{-\triangle \Delta C T}$ method was utilized to calculate the expression of PDCD4 mRNA, GAS5 and miR-21. Option Monitor software (version 2.03, MJ Research, Cambridge, MA) was utilized to analyze the expression data.

Cell culture and transfection

The alpha modification of Eagle medium (GIBCO/ Invitrogen, Carlsbad, CA) was utilized to culture the endothelial cells in 48-well plates at $5 \% \quad \mathrm{CO}_{2}$ and $37^{\circ} \mathrm{C}$. A
Table 1. Demographic and clinicopathological characteristics of the participants in this study

\begin{tabular}{|c|c|c|c|c|c|}
\hline Characteristic & Atherosclerosis $(-)$ & $\mathrm{N}=681$ & Atherosclerosis (+) & $\mathrm{N}=624$ & P value \\
\hline Age (year) & $63.81 \pm 11.48$ & & $64.17 \pm 9.71$ & & 0.543 \\
\hline Gender M/F & $412 / 269$ & & $365 / 259$ & & 0.461 \\
\hline Hypertension (\%) & $412(60.50)$ & & $372(59.62)$ & & 0.744 \\
\hline Diabetes mellitus (\%) & $118(17.33)$ & & 109 (17.47) & & 0.950 \\
\hline Hypercholesterolemia (\%) & $158(23.20)$ & & $144(23.08)$ & & 0.956 \\
\hline Smoking (\%) & $185(27.17)$ & & $166(26.60)$ & & 0.818 \\
\hline
\end{tabular}




\section{Cellular Physiology Cell Physiol Biochem 2018;49:1431-1443 \begin{tabular}{l|l|l} 
and Biochemistry & DOI: 10.1159/000493447 & $\begin{array}{l}\text { C } 2018 \text { The Author(s). Published by S. Karger AG, Basel } \\
\text { www.karger.com/cpb }\end{array}$
\end{tabular} \\ Shen et al.: Rs145204276 was Associated with Atherosclerosis}

Lipofectamine ${ }^{\circledR}$ RNAiMAX Transfection Reagent (Applied Biosystems, MA) was utilized to transfect the cells with GAS5 siRNA, miR-21 mimics, miR-21 inhibitors or PDCD4 siRNA (Sunbio, Shanghai, China) following the protocol provided by the manufacturer.

\section{Cell proliferation assay}

A Cell Counting Kit-8 (Beyotime, shanghai, China) was utilized to carry out cell proliferation assay according to the supplier's instruction. In brief, endothelial cells were seeded into 96-well plates at a final density of $2 \times 10^{5}$ cells/well and then transfected with GAS5 siRNA, miR-21 mimics or PDCD4 siRNA. A SpectraMax® i3x microplate reader (Molecular Devices, Sunnyvale, $C A$ ) was utilized to detect cell viability at the absorbance of $450 \mathrm{~nm}$. All tests were carried out three times.

\section{Luciferase assay to identify the interaction between 3'UTR of PDCD4 and miR-21}

Commonly cited prediction programs, such as miRBase (http://www.mirbase.org), were utilized to predict that PDCD4 was a target of miR-21. Subsequently, the 3'-UTR of PDCD4, which contained the miR-21 binding site, was amplified by PCR. Afterwards, we mutated the seed region of target site of miR-21, 3'-UTR of PDCD4 and 3'-UTR of mutant PDCD4. These mutation products were inserted into a pmirGLO DualLuciferase miRNA TargetExpression Vector (Promega, Madison, WI) and then FuGENE-HD transfection reagent (Promega, Madison, WI) was utilized to co-transfect endothelial cells with $25 \mathrm{nM}$ miR-21 mimics) (Gene Pharma, Shanghai, China) and 150 ng plasmid (pmirGLO-mutPDCD4-3'-UTR or pmirGLO-PDCD4-3'UTR) in accordance with the manufacturer's recommendation. The cells were harvested 24 hours posttransfection. A Dual-Glo Luciferase Assay System (Promega, Madison, WI) was utilized to analyze the luciferase activity, while a Renilla luciferase reporter served as the internal control for transfection. Finally, a GLoMax 20/20 system (Promega, Madison, WI) was utilized to measure the relative luciferase activity. All experiments were run in triplicate.

\section{Luciferase assay to determine the transcription ability of GAS5 promoters with different genotypes}

Luciferase assays were performed to determine whether the polymorphism rs145204276 affects the expression of GAS5. Briefly, PCR was utilized to amplify full promoter fragment from DNA isolated from the blood samples of the participants. The produced GAS5 promoter-luciferase reporter plasmids carried either rs 145204276 INS or DEL allele. In the next step, sequencing was performed to confirm the rs145204276 alleles of the reporters constructs. Subsequently, endonuclease (NEB, BioLabs Inc., CA) was utilized to digest the psiCHECK2 vector (Promega, MD) and the amplified fragments, respectively. Afterwards, the PCR products were cloned into a psiCHECK2 (Promega, MD) vector. Endothelial cells were incubated in 48-well plates and co-transfected with $50 \mathrm{nM}$ miR-21mimics in conjunction with $50 \mathrm{ng}$ psiCHECK2 vectors using Lipofectamine 2000 (Life Technologies, Carlsbad, CA). The cells were harvested 24 hours post-transfection and a Dual-Glo Luciferase Assay System (Promega, Madison, WI) was utilized to measure the luciferase activity in transfected cells. At the same time, Renilla luciferase reporter served as the internal control to normalize the transfection of firefly luciferase. All experiments were run in triplicate.

\section{Luciferase assay to determine the interaction between miR-21 and GAS5}

The oligo of miR-21 was purchased from GeneChem (Shanghai, China) and inserted into multiple restrictive sites of a pGL3 vector. The mutations in the sequence were introduced using a site-directed mutagenesis kit. The endothelial cells $\left(2 \times 10^{6}\right)$ were plated in $100-\mathrm{mm}$ cellculture dishes and allowed to reach $60-80 \%$ confluence after $24 \mathrm{~h}$ of culturing. Subsequently, endothelial cells were co-transfected with 3 mg of DNA of the reporter constructs pGL3-miR-21-WT or pGL3-miR-21-Mut in conjunction with pCDNAGAS5, or an empty vector. The cells were harvested 24 hours post-transfection and analyzed using the DualGlo luciferase assay as mentioned earlier.

\section{Western blot analysis}

Cold PBS was utilized to wash the cells twice, and RIPA (radio immunoprecipitation) was utilized to lyse the cells at $4^{\circ} \mathrm{C}$. Subsequently, the lysates were subjected to centrifuge for $5 \mathrm{~min}$ at $14,000 \mathrm{~g}$. A BCA Protein Assay Kit (Pierce Biotechnology, Rockford, IL) was utilized to measure the total protein concentration. Subsequently, proteins in the samples were resolved using 10\% SDS-PAGE and then transferred onto a polyvinylidenedifluoride transfer membrane (Millipore, Bedford, MA). In the next step, 0.1\%Tween-20 


\section{Cellular Physiology Cell Physiol Biochem 2018;49:1431-1443 \\ \begin{tabular}{l|l} 
DOI: 10.1159/000493447 & $\begin{array}{l}\text { O } 2018 \text { The Author(s). Published by S. Karger AG, Basel } \\
\text { www.karger.com/cpb }\end{array}$
\end{tabular} \\ Shen et al.: Rs145204276 was Associated with Atherosclerosis}

(TBST) containing 5\% nonfat milk was used to block the membrane, followed by incubation with specific primary anti-PDCD4 antibodies (1: 5, 000 dilution, Santa Cruz Biotechnology, Inc., Santa Cruz, CA) and anti$\beta$-actin antibodies (1: 10, 000 dilution, ProMab Biotechnologies, Richmond, CA). After a 12-hour incubation, the membrane was rinsed with PBS and incubated with horseradish peroxidase (HRP) conjugated secondary antibodies (1:12000 dilution, Bioworld Technology, Inc., Minneapolis, MN) for another 30 minutes at room temperature. Finally, enhanced chemiluminescence (ECL) was utilized to visualize the protein bands, whose intensities were analyzed by ImageJ software (http://rsb.info.nih.gov/ij).

\section{Cell apoptosis analysis}

Cellular apoptosis was detected using an Annexin-V-FITC/PI double staining assay. In brief, endothelial cells were seeded into 96-well plates at a final density of $2 \times 10^{5}$ cells/well and transfected with GAS5 siRNA, miR-21 mimics or PDCD4 siRNA. After 48 hours incubation, the cell were harvested, washed with cold PBS and resuspended in an Annexin-V binding buffer at a final density of $1 \times 10^{6}$ cells $/ \mathrm{mL}$. Subsequently, the apoptotic profile of the cells was and analyzed with flow cytometry.

\section{Statistical analysis}

All results were shown as the means \pm SD (standard deviation). Student's $t$ test was performed to analyze the differences between two groups, while a P value of less than 0.05 was considered statistically significant.

\section{Results}

Demographic, clinicopathological and genotypic parameters of the participants recruited in this study

A total of 1, 306 subjects were enrolled for our research, which consisted of 681 atherosclerosis patients and 624 healthy subjects. The demographic and clinicopathological characteristics of the participants, such as gender, age, hypertension, diabetes mellitus, hypercholesterolemia, and smoking history, are displayed in Table 1. Student t-test was used to analyze the demographic and clinicopathological characteristics of participants between these two groups, and it was found that all above clinicopathological characteristics of participants displayed no obvious differences between the two groups. The distribution of genotypes in both case and control groups followed the HWE $(\mathrm{P}>0.05)$. Furthermore, a logistic regression test was used to analyze the genotypes, and it was found that the ins/del or del/ del genotypes were significantly associated with a decreased risk of atherosclerosis compared with the INS/INS genotypes (values of adjusted odds ratio: 0.74 and 0.40 , respectively). Similarly, we found that the DEL allele was significantly associated with a reduced risk of atherosclerosis compared with the INS allele (adjusted odds ratio: 0.57), as shown in Table 2.

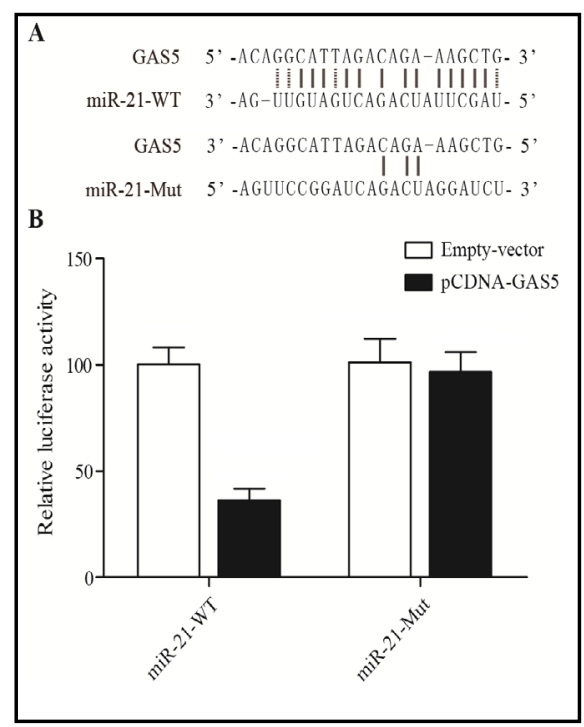

Fig. 1. A: MiR-21 contained a putative binding site of GAS5. B: GAS5 substantially decreased the luciferase activity of wildtype miR-21.

Table 2. Association between genotype and allele of rs145204276 and risk of atherosclerosis

\begin{tabular}{|c|c|c|c|c|c|}
\hline Genotype & Atherosclerosis (-) & $\mathrm{N}=681$ & Atherosclerosis (+) & $\mathrm{N}=624$ & Odds ratio and $\mathrm{P}$ value \\
\hline \multicolumn{6}{|c|}{ Rs145204276 } \\
\hline \multicolumn{6}{|l|}{ Genotype } \\
\hline ins/ins & $325(47.7)$ & & $235(37.7)$ & & \\
\hline ins/del & 305 (44.8) & & $296(47.4)$ & & $0.74(0.59-0.94) \quad \mathrm{P}=0.0128$ \\
\hline $\mathrm{del} / \mathrm{del}$ & $51(7.5)$ & & $93(14.9)$ & & $0.40(0.27-0.58) \quad P<0.001$ \\
\hline \multicolumn{6}{|l|}{ Allele } \\
\hline ins & $955(70.1)$ & & $358(57.3)$ & & $0.57(0.47-0.70) \quad P<0.001$ \\
\hline del & $407(29.9)$ & & $266(42.7)$ & & \\
\hline
\end{tabular}




\section{Cellular Physiology Cell Physiol Biochem 2018;49:1431-1443 and Biochemistry \begin{tabular}{l|l} 
DOI: 10.1159/000493447 & $\begin{array}{l}\text { (c) } 2018 \text { The Author(s). Published by S. Karger AG, Basel } \\
\text { www.karger.com/cpb }\end{array}$
\end{tabular}

\section{GAS5 regulates miR-21}

LncRNAs were generally considered as molecular sponges or competing endogenous RNAs in the regulation of muscle concentration. Previously, LncRNA GAS5 and miR-21 have been shown to be significantlyassociated withatherosclerosis. Therefore, an in-silicon analysis was performed in this study to investigate whether GAS5 served as molecular sponges or competing endogenous RNAs to mediate miR-21 expression. As shown in Fig. 1A, miR-21 contains a putative binding site for GAS5 (Fig. 1A). Subsequently, the luciferase constructs containing wild or mutant type miR-21 were used to validate whether GAS5 contains a functional target for miR21. As shown in Fig. 2B, overexpression of GAS5 decreased luciferase activity of wildtype miR-21 but not that of mutant miR-21, suggesting that GAS5 served as a competing endogenous RNA to mediate miR-21 expression.

\section{Rs145204276 influenced transcriptional activity of GAS5}

Because rs145204276 is located at the transcriptional start site of GAS5, and because different genotypes of rs145204276 were shown to affect the expression level of GAS5, the effect of rs145204276 on the transcriptional activity of GAS5 promoter region was explored using luciferase assays. As shown in Fig. $2 \mathrm{~A}$, the rs145204276 polymorphism INS and DEL alleles were cloned into the vector upstream of the luciferase reporter gene. As shown in Fig. 2B, the luciferase activity of cells was apparently increased after the cells were transfected with rs145204276 INS or DEL allele. Moreover, the presence of rs145204276 DEL allele significantly increased the transcriptional activity of GAS5 promoter compared with that containing the INS allele.

\section{PDCD4 was a virtual target gene of miR- 21}

Bioinformatics algorithm analysis was performed using TargetScan to identify that $P D C D 4$ was a direct target gene of miR21 , with a binding site located on the 3'UTR of PDCD4 (Fig. 3A). Subsequently, luciferase assays were conducted using constructs containing wild-type or mutant 3'UTR of PDCD4 and the results showed that miR-21 directly targeted $P D C D 4$, as the luciferase activity of cells

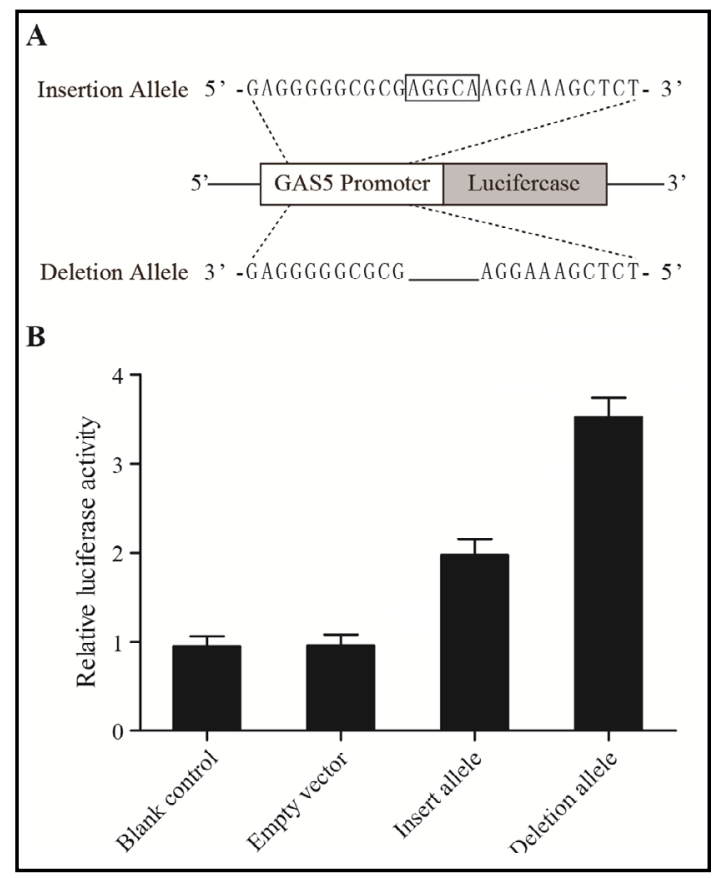

Fig. 2. A: Rs145204276 polymorphism INS/ INS allele and DEL/DEL allele were located on the promoter of GAS5, and were inserted into a location upstream of the luciferase reporter gene. B: Transfection with rs145204276 insert or deletion allele increased the luciferase activity of GAS5, while the effect of deletion allele was even stronger.

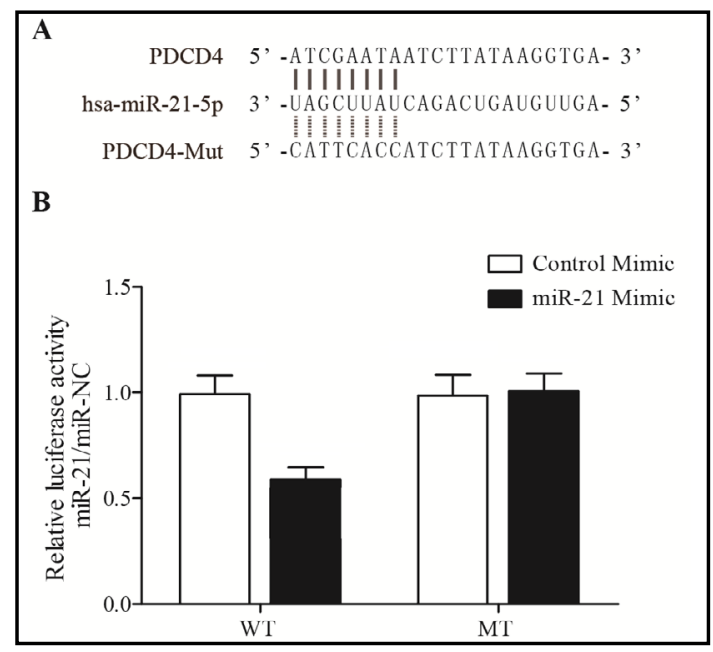

Fig. 3. A: PDCD4 was identified as a candidate target gene of miR-21, with the 'seed sequence' located in the 3'UTR of PDCD4. B: MiR-21 dramatically downregulated the luciferase activity of wild-type PDCD4, but not that of mutant PDCD4. 


\section{Cellular Physiology Cell Physiol Biochem 2018;49:1431-1443

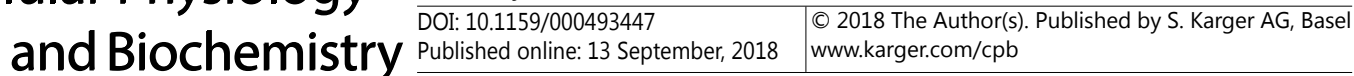 Shen et al.: Rs145204276 was Associated with Atherosclerosis}

Fig. 4. A: The viability of cells genotyped as INS/INS was decreased following the treatment with high glucose. B: The viability of cells genotyped as DEL/ DEL was decreased following the treatment with high glucose. C: The apoptosis of cells genotyped as INS/INS was increased after the treatment with high glucose. D: The apoptosis of cells genotyped as DEL/ DEL was increased after the treatment with high glucose.

transfected with wild PDCD4 was evidently down-regulated but the luciferase activity of cells transfected with mutant PDCD4 remained unchanged as that of the scramble control (Fig. 3B), indicating that miR-21 directly and negatively regulated PDCD4 expression.

High glucose affected the proliferation and apoptosis of endothelial cells (ECS)

High glucose is considered as a key factor that can induce atherosclerosis via regulating the viability and apoptosis of ECs. Therefore, the effect of SNP DEL/DEL and INS/INS on the viability and apoptosis of HUVECs was examined in the presence of high glucose. As shown in Fig. 4, high glucose significantly inhibited the growth rate of both genotypes of HUVECs (DEL/DEL or INS/INS, as shown in Fig. 4A and 4B). However, the inhibitory effect of glucose in HUVECs (INS/INS) was stronger than that in HUVECs (DEL/DEL). In addition, the presence of high glucose significantly elicited the apoptosis of both genotypes of HUVECs (Fig. 4C and 4D).

Rs145204276 polymorphism in the promoter region of GAS5 regulated the expression of miR-21

PDCD4 has been shown to act as a target gene of miR-21 (Fig. 3), which in turn was directly targeted by GAS5 (Fig. 1). Therefore, we wanted to investigate whether the SNP rs145204276 (DEL/DEL or INS/INS) affects PDCD4 expression. As shown in Fig. 5A, GAS5 was highly expressed in cells carrying the DEL/DEL genotype compared with that in cells carrying the INS/INS group. In contrast, the expression of miR-21 was higher in the INS/INS group than that in the DEL/DEL group (Fig. 5B). Interestingly, both levels of PDCD4 mRNA (Fig. 5C) and protein (Fig. 5D) were increased in the DEL/DEL group in comparison with
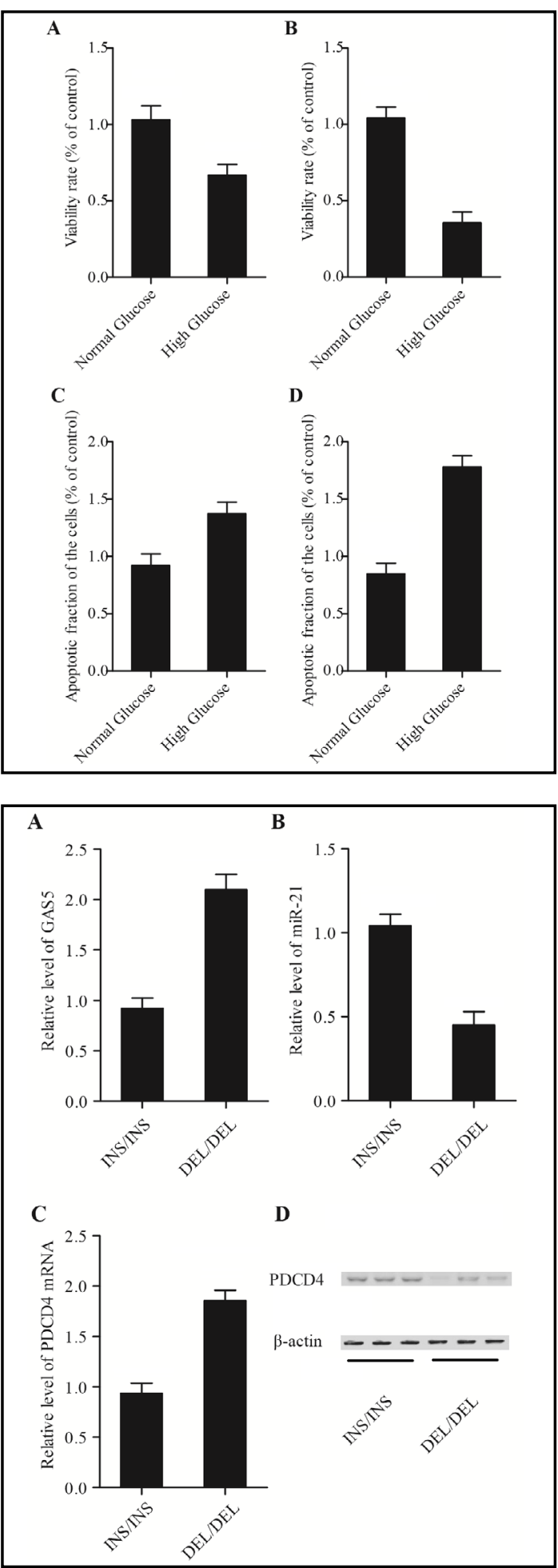

Fig. 5. Rs145204276 polymorphism affected the expression of miR-21 and PDCD4. A: GAS5 expression was much higher in the DEL/DEL cells. B: miR-21 expression was much lower in the DEL/DEL cells. C: PDCD4 mRNA level was much higher in the DEL/DEL cells. D: PDCD4 protein level was much higher in the DEL/DEL cells. 
that in the INS/INS group, suggesting that the DEL allele of the rs145204276 polymorphism in GAS5 dramatically up-regulated the expression of both GAS5and PDCD4. Alternation of
GAS5 influenced
the expression of
PDCD4 as well as
the proliferation
and apoptosis of
ECs further
To explore the role of GAS5 in the control of atherosclerosis by affecting the proliferation and apoptosis of ECs, we transfected two types of EC cells, i.e., genotyped as INS/ INS and DEL/DEL, respectively, with GAS5 siRNA or miR21 mimics. As shown in Fig. 6 and 7, GAS5 siRNA and miR-21 mimics significantly decreased the level of GAS5 in cells genotyped as INS/INS

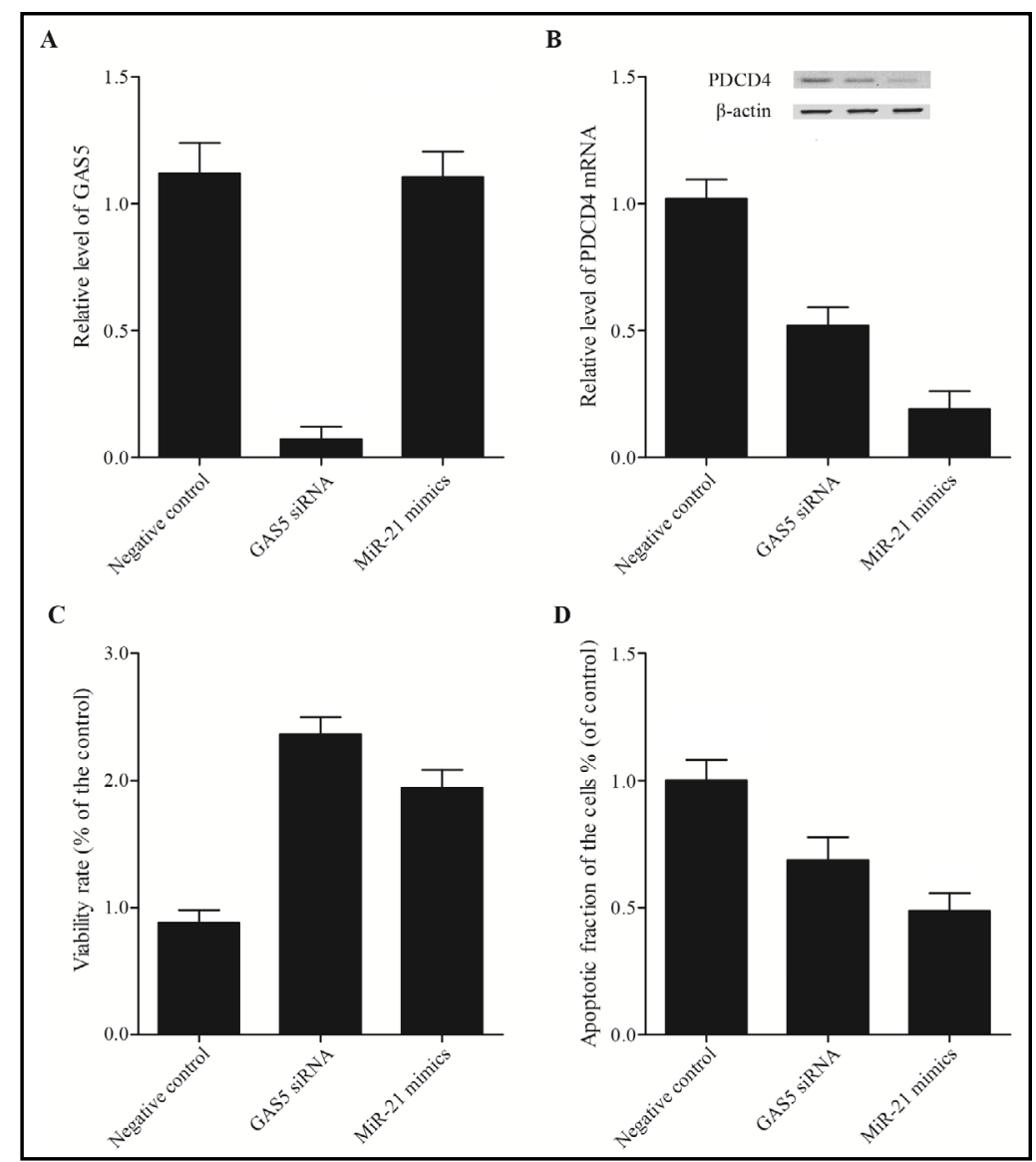

Fig. 6. The effect of GAS5 and miR-21 on the proliferation and apoptosis of cells genotyped as INS/INS. A: GAS5 level in cells transfected with GAS5 siRNA and miR-21 mimics was significantly reduced. B: PDCD4 level in cells transfected with GAS5 siRNA and miR-21 mimics was significantly reduced. C: Transfecting the cells with GAS5 siRNA and miR-21 mimics significantly increased cell viability. D: Transfecting the cells with GAS5 siRNA and miR-21 mimics significantly inhibited cell apoptosis.

(Fig. 6A) and DEL/DEL (Fig. 7A). In addition, the inhibitory effects of GAS5 siRNA or miR-21 mimics on GAS5 expression were stronger in the INS/INS group than those in the DEL/DEL group. Compared with the NC group, GAS5 siRNA and miR-21 mimics remarkably decreased the expression of both PDCD4 mRNA and protein in cells genotyped as INS/INS (Fig. 6B) and DEL/DEL (Fig. 7B). Taken together, the inhibitory effects of GAS5 siRNA or miR-21 mimics on PDCD4 expression was stronger in the INS/INS cells than those in the DEL/DEL cells. Furthermore, MTT assay and flow cytometry analysis were performed to detect the effect of GAS5 on the proliferation and apoptosis of HUVECs. As shown in Fig. 6C and 7C, GAS5 siRNA and miR-21 mimics remarkably increased cells growth in cells genotyped as INS/INS (Fig. 6C) and DEL/DEL (Fig. 7C), while attenuating the apoptotic rate of cells genotyped as INS/ INS (Fig. 6D) and DEL/DEL (Fig. 7D). In addition, and the inhibitory effects of GAS5 siRNA or miR-21 mimics on cell viability and apoptosis were stronger in the INS/INS cells than those in the DEL/DEL cells. In summary, GAS5 attenuated the proliferation of HUVECs by targeting PDCD4 and accelerating apoptosis, and the effect of GAS5 was stronger in the INS/INS cells. 


\begin{abstract}
Discussion
In this study, we enrolled a total of 1, 306 subjects, which included 681 atherosclerosis patients and 624 healthy subjects. Logistic regression test was used to analyze the genotypes of rs145204276 polymorphism in these patients and the results showed that the INS/DEL or DEL/DEL genotypes were significantly associated with the decreased risk of atherosclerosis compared with that of the ins/ins genotype (values of adjusted odds ratio: 0.74 and 0.40 , respectively).
\end{abstract} Similarly, we found that the DEL allele was significantly associated with a reduced risk of at herosclerosis compared with the INS allele (adjusted odds ratio: 0.57$)$. It has also been revealed that the expression of three lncRNAs, i.e., Zfas1, SNHG6 and GAS5, was substantially elevated in the plaque of atherosclerosis patients [28, 29]. Interestingly, an earlier study has suggested that non-coding RNAs Zfas1 and GAS5 acted as tumor inhibitors, while the down-regulation of IncRNA GAS5 was found in prostate cancer, non-small cell lung cancer, breast cancer and renal cell carcinoma [30-33].Furthermore, an association between the rs145204276 polymorphism in the promoter region of GAS5 and the risk of HCC has also been identified. Moreover, rs145204276 may be functionally involved in oncogenesis via modulating the methylation status of a CpG island situated in the GAS5 promoter region, thus influencing the activity and expression of GAS5 [25]. In this study, we conducted luciferase reporter assays using vectors carrying rs145204276 polymorphism INS and DEL alleles to determine the effect of rs145204276 on the transcriptional activity of GAS5. Our results showed that in the presence of rs145204276 DEL allele, the transcription of GAS5 promoter was significantly promoted compared with that of the rs145204276 INS allele.

LncRNAs bind to miRNAs and act as endogenous "sponges" to modulate the functions of miRNAs [34, 35]. However, the mechanisms underlying the trans-regulatory functions of IncRNA/miRNA remain elusive. Furthermore, lncRNA CASC2, a tumor inhibitor, exhibits 
an anti-cancer function partly via the inhibition of miR-21 activity [36]. In addition, GAS5 inhibits miR-21 expression via a posttranscriptional regulatory pathway involving the RISC complex, while GAS5 contains a region of complementarity with miR-21 [37]. It was also revealed that miR-21 modulates the expression of $P D C D 4$ mRNA and affects its degradation, resulting in reduced expression of $P D C D 4$ proteins [38]. Furthermore, the elevation of miR21 expression and the loss of $P D C D 4$ activity have been identified in a wide range of cancers [38]. Intriguingly, the synthesis of $P D C D 4$ in these cancer cells is decreased, although there is an elevated level of both cytoplasmic miR-21 and HuR in primary Glioblastoma cells [39]. In this study, using both in-silicon analysis and luciferase assays, we confirmed the regulatory relationship between miR-21 and GAS5, as well as the regulatory association between miR21 and PDCD4 in ECs.

It is believed that the apoptosis of ECs leads to the dysfunction or impairment of intact endothelial monolayer, which in turn results in inflammatory reactions, monocyte adhesion, lipid accumulation, and atherosclerotic lesions [4]. It has also been shown that ECs play important roles in the occurrence of atherosclerosis and the apoptosis of ECs may lead to reduced ability of endothelium to protect against inflammation, to enhance immunity and to maintain lipid homeostasis [40]. In this study, we found that high glucose significantly suppressed the proliferation and induced the apoptosis of ECs genotyped as either DEL/DEL or INS/INS, and the effect of high glucose was stronger in INS/INS cells.

$P D C D 4$ was first discovered in tumor cells and blood, where the expression of PDCD4 was down-regulated but increased upon apoptosis [41]. The human PDCD4 gene is situated on chromosome 10q24. Analysis of the relevant protein sequence in this region has shown that PDCD4consists of 469 amino acids, which form two conserved $\alpha$-helical MA-3 domains and two basic domains at the $\mathrm{COOH}$ terminus and $\mathrm{NH}_{2}$ terminus, respectively. A recent study has also investigated the biological roles of $P D C D 4$ and its underlying molecular mechanisms [41]. It was shown that PDCD4 could regulate the functions of molecules including Sp1/ Sp3, urokinase-receptor (u-PAR), JNK/c-Jun/activator protein 1 (AP-1), carbonic anhydrase II, ornithine decarboxylase, Cdk4 and p21Waf1/Cip1 [41]. Therefore, it is hypothesized that $P D C D 4$ plays a regulatory role in tumor cell proliferation, invasion and apoptosis [6]. In general, $P D C D 4$ acts as a potent tumor inhibitor [6]. For example, $P D C D 4$ was found to suppress neoplastic growth and transformation, and hence is regarded as a potential antineoplastic target for novel cancer therapies [42]. In addition, PDCD4 is believed to induce apoptosis through the stimulation of the caspase-3 pathway [43].It has also been shown that the activity of caspase- 3 plays a crucial role in inducing PH dyshomeostasis and in promoting endothelial apoptosis [26].In this study, we investigated whether the alternation of GAS5 influenced the expression of $P D C D 4$ as well as the proliferation and apoptosis of EC cells. We found that GAS5 attenuated the proliferation of HUVECs by targeting PDCD4 and accelerating the apoptosis of HUVECs. Interestingly, PDCD4 also acts as a pro-inflammatory protein and its expression is elevated in foam cells derived from ox-LDL-stimulated macrophages and in mice suffering from atherosclerosis, further demonstrating the implication of PDCD4 in the occurrence of atherosclerosis [44]. Additionally, the MAPK pathway plays an important role in inflammatory disorders, such as atherosclerosis [45]. It has been shown that the MAPK signaling could activate p38 and JNK, and hence regulates the activity of pro- and anti-inflammatory cytokines (IL-10 and TNF- $\alpha$ ) in macrophages [46]. Furthermore, Jiang et al. observed that, in PDCD4 deficient mice, the function of IL-10 was alleviated by the suppression of the p38/ERK-c-Maf pathway [47].

In spite of its important findings, the present study suffers from a certain limitations: First, the sample size in this study was relatively small due to the limited time and funding , thus may constrain the credibility of relevant statistical tests. Secondly, the tissue samples of veins rather than arteries were used in this study. Thus, the results reported here may be inconsistent with those reported by others. Nevertheless, further studies with larger sample sizes and populations with different genetic backgrounds, coupled with animal model studies will lead to a clearer understanding of the molecular interactions involved in this field and a more robust conclusion.

\section{KARGER}




\section{Cellular Physiology Cell Physiol Biochem 2018;49:1431-1443 \begin{tabular}{ll|l} 
and Biochemistry Published online: 13 September, 2018 & $\begin{array}{l}\text { (c) } 2018 \text { The Author(s). Published by S. Karger AG, Basel } \\
\text { www.karger.com/cpb }\end{array}$ \\
\hline
\end{tabular}

\section{Conclusion}

Taken together, our findings suggested that rs145204276 was associated with the risk of atherosclerosis by affecting the methylation status of the GAS5 promoter and its transcriptional activity. Thus, rs145204276 could serve as a potential therapeutic target for the treatment of atherosclerosis. Results from this study demonstrated that lncRNAs (GAS5) might be involved in the atherosclerosis via targeting both miR-and PDCD4. In summary, our findings provide new insight into the pathogenic mechanism and the role of GAS5 in atherosclerosis.

\section{Disclosure Statement}

The authors claim to have no conflict of interests.

\section{References}

1 Moran AE, Roth GA, Narula J, Mensah GA: 1990-2010 global cardiovascular disease atlas. Glob Heart 2014;9:3-16.

-2 Lovren F, Pan Y, Quan A, Singh KK, Shukla PC, Gupta N, Steer BM, Ingram AJ, Gupta M, Al-Omran M, Teoh H, Marsden PA, Verma S: MicroRNA-145 targeted therapy reduces atherosclerosis. Circulation 2012;126:S8190.

3 Dimmeler S, Hermann C, Zeiher AM: Apoptosis of endothelial cells. Contribution to the pathophysiology of atherosclerosis? Eur Cytokine Netw 1998;9:697-698.

-4 Menghini R, Casagrande V, Marino A, Marchetti V, Cardellini M, Stoehr R, Rizza S, Martelli E, Greco S, Mauriello A, Ippoliti A, Martelli F, Lauro R, Federici M: MiR-216a: a link between endothelial dysfunction and autophagy. Cell Death Dis 2014;5:e1029.

5 Sima AV, Stancu CS, Simionescu M: Vascular endothelium in atherosclerosis. Cell Tissue Res 2009;335:191203.

6 Lankat-Buttgereit B, Goke R: The tumour suppressor Pdcd4: recent advances in the elucidation of function and regulation. Biol Cell 2009;101:309-317.

7 Cheng Y, Liu X, Zhang S, Lin Y, Yang J, Zhang C: MicroRNA-21 protects against the H(2)O(2)-induced injury on cardiac myocytes via its target gene PDCD4. J Mol Cell Cardiol 2009;47:5-14.

-8 Davis BN, Hilyard AC, Lagna G, Hata A: SMAD proteins control DROSHA-mediated microRNA maturation. Nature 2008;454:56-61.

-9 Wang F, Zhao XQ, Liu JN, Wang ZH, Wang XL, Hou XY, Liu R, Gao F, Zhang MX, Zhang Y, Bu PL: Antagonist of microRNA-21 improves balloon injury-induced rat iliac artery remodeling by regulating proliferation and apoptosis of adventitial fibroblasts and myofibroblasts. J Cell Biochem 2012;113:2989-3001.

-10 Lin Y, Liu X, Cheng Y, Yang J, Huo Y, Zhang C: Involvement of MicroRNAs in hydrogen peroxide-mediated gene regulation and cellular injury response in vascular smooth muscle cells. J Biol Chem 2009;284:79037913.

11 Ge C, Song J, Chen L, Wang L, Chen Y, Liu X, Zhang Y, Zhang L, Zhang M: Atheroprotective pulsatile flow induces ubiquitin-proteasome-mediated degradation of programmed cell death 4 in endothelial cells. PLoS One 2014;9:e91564.

12 Finishing the euchromatic sequence of the human genome. Nature 2004;431:931-945.

13 Trefzer U, Rietz N, Chen Y, Audring H, Herberth G, Siegel P, Reinke S, Koniger P, Wu S, Ma J, Liu Y, Wang H, Sterry W, Guo Y: SM5-1: a new monoclonal antibody which is highly sensitive and specific for melanocytic lesions. Arch Dermatol Res 2000;292:583-589.

14 Wang L, Yang F, Jia LT, Yang AG: Missing Links in Epithelial-Mesenchymal Transition: Long Non-Coding RNAs Enter the Arena. Cell Physiol Biochem 2017;44:1665-1680.

15 Scheuermann JC, Boyer LA: Getting to the heart of the matter: long non-coding RNAs in cardiac development and disease. EMBO J 2013;32:1805-1816. 


\section{Cellular Physiology Cell Physiol Biochem 2018;49:1431-1443 \begin{tabular}{l|l} 
DOI: 10.1159/000493447 & Ond Biochemistry 2018 The Author(s). Published by S. Karger AG, Basel \\
wwww.karger.com/cpb
\end{tabular}

16 Shen S, Jiang H, Bei Y, Xiao J, Li X: Long Non-Coding RNAs in Cardiac Remodeling. Cell Physiol Biochem 2017;41:1830-1837.

17 Huang G, Kang Y, Huang Z, Zhang Z, Meng F, Chen W, Fu M, Liao W: Identification and Characterization of Long Non-Coding RNAs in Osteogenic Differentiation of Human Adipose-Derived Stem Cells. Cell Physiol Biochem 2017;42:1037-1050.

18 Gao W, Zhu M, Wang H, Zhao S, Zhao D, Yang Y, Wang ZM, Wang F, Yang ZJ, Lu X, Wang LS: Association of polymorphisms in long non-coding RNA H19 with coronary artery disease risk in a Chinese population. Mutat Res 2015;772:15-22.

19 Wu G, Cai J, Han Y, Chen J, Huang ZP, Chen C, Cai Y, Huang H, Yang Y, Liu Y, Xu Z, He D, Zhang X, Hu X, Pinello L, Zhong D, He F, Yuan GC, Wang DZ, Zeng C: LincRNA-p21 regulates neointima formation, vascular smooth muscle cell proliferation, apoptosis, and atherosclerosis by enhancing p53 activity. Circulation 2014;130:1452-1465.

20 Raitoharju E, Lyytikainen LP, Levula M, Oksala N, Mennander A, Tarkka M, Klopp N, Illig T, Kahonen M, Karhunen PJ, Laaksonen R, Lehtimaki T: miR-21, miR-210, miR-34a, and miR-146a/b are up-regulated in human atherosclerotic plaques in the Tampere Vascular Study. Atherosclerosis 2011;219:211-217.

21 Feng J, Li A, Deng J, Yang Y, Dang L, Ye Y, Li Y, Zhang W: miR-21 attenuates lipopolysaccharide-induced lipid accumulation and inflammatory response: potential role in cerebrovascular disease. Lipids Health Dis 2014;13:27.

-22 Gong WJ, Yin JY, Li XP, Fang C, Xiao D, Zhang W, Zhou HH, Li X, Liu ZQ: Association of well-characterized lung cancer IncRNA polymorphisms with lung cancer susceptibility and platinum-based chemotherapy response. Tumour Biol 2016;37:8349-8358.

23 Song J, Ahn C, Chun CH, Jin EJ: A long non-coding RNA, GAS5, plays a critical role in the regulation of miR-21 during osteoarthritis. J Orthop Res 2014;32:1628-1635.

-24 Hu L, Ye H, Huang G, Luo F, Liu Y, Yang X, Shen J, Liu Q, Zhang J: Long noncoding RNA GAS5 suppresses the migration and invasion of hepatocellular carcinoma cells via miR-21. Tumour Biol 2016;37:2691-2702.

-25 Tao R, Hu S, Wang S, Zhou X, Zhang Q, Wang C, Zhao X, Zhou W, Zhang S, Li C, Zhao H, He Y, Zhu S, Xu J, Jiang Y, Li L, Gao Y: Association between indel polymorphism in the promoter region of lncRNA GAS5 and the risk of hepatocellular carcinoma. Carcinogenesis 2015;36:1136-1143.

-26 White K, Dempsie Y, Caruso P, Wallace E, McDonald RA, Stevens H, Hatley ME, Van Rooij E, Morrell NW, MacLean MR, Baker AH: Endothelial apoptosis in pulmonary hypertension is controlled by a microRNA/ programmed cell death 4/caspase-3 axis. Hypertension 2014;64:185-194.

-27 Song H, Wu F, Zhang Y, Wang F, Jiang M, Wang Z, Zhang M, Li S, Yang L, Wang XL, Cui T, Tang D: Irisin promotes human umbilical vein endothelial cell proliferation through the ERK signaling pathway and partly suppresses high glucose-induced apoptosis. PLoS One 2014;9:e110273.

28 Chen L, Yao H, Hui JY, Ding SH, Fan YL, Pan YH, Chen KH, Wan JQ, Jiang JY: Global transcriptomic study of atherosclerosis development in rats. Gene 2016;592:43-48.

-29 Yan J, Zhang Y, She Q, Li X, Peng L, Wang X, Liu S, Shen X, Zhang W, Dong Y, Lu J, Zhang G: Long Noncoding RNA H19/miR-675 Axis Promotes Gastric Cancer via FADD/Caspase 8/Caspase 3 Signaling Pathway. Cell Physiol Biochem 2017;42:2364-2376.

-30 Pickard MR, Mourtada-Maarabouni M, Williams GT: Long non-coding RNA GAS5 regulates apoptosis in prostate cancer cell lines. Biochim Biophys Acta 2013;1832:1613-1623.

-31 Shi X, Sun M, Liu H, Yao Y, Kong R, Chen F, Song Y: A critical role for the long non-coding RNA GAS5 in proliferation and apoptosis in non-small-cell lung cancer. Mol Carcinog 2015;54 Suppl 1:E1-E12.

-32 Mourtada-Maarabouni M, Pickard MR, Hedge VL, Farzaneh F, Williams GT: GAS5, a non-protein-coding RNA, controls apoptosis and is downregulated in breast cancer. Oncogene 2009;28:195-208.

-33 Qiao HP, Gao WS, Huo JX, Yang ZS: Long non-coding RNA GAS5 functions as a tumor suppressor in renal cell carcinoma. Asian Pac J Cancer Prev 2013;14:1077-1082.

-34 Cesana M, Cacchiarelli D, Legnini I, Santini T, Sthandier O, Chinappi M, Tramontano A, Bozzoni I: A long noncoding RNA controls muscle differentiation by functioning as a competing endogenous RNA. Cell 2011;147:358-369.

35 Gong LC, Xu HM, Guo GL, Zhang T, Shi JW, Chang C: Long Non-Coding RNA H19 Protects H9c2 Cells against Hypoxia-Induced Injury by Targeting MicroRNA-139 Cell Physiol Biochem 2017;44:857-869.

-36 Wang P, Liu YH, Yao YL, Li Z, Li ZQ, Ma J, Xue YX: Long non-coding RNA CASC2 suppresses malignancy in human gliomas by miR-21. Cell Signal 2015;27:275-282. 


\section{Cellular Physiology Cell Physiol Biochem 2018:49:1431-1443

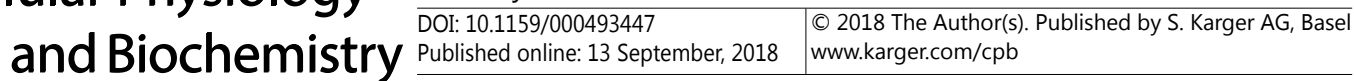 \\ Shen et al.: Rs145204276 was Associated with Atherosclerosis}

-37 Zhang Z, Zhu Z, Watabe K, Zhang X, Bai C, Xu M, Wu F, Mo YY: Negative regulation of IncRNA GAS5 by miR21 Cell Death Differ 2013;20:1558-1568.

-38 Asangani IA, Rasheed SA, Nikolova DA, Leupold JH, Colburn NH, Post S, Allgayer H: MicroRNA-21 (miR-21) post-transcriptionally downregulates tumor suppressor Pdcd4 and stimulates invasion, intravasation and metastasis in colorectal cancer. Oncogene 2008;27:2128-2136.

-39 Gaur AB, Holbeck SL, Colburn NH, Israel MA: Downregulation of Pdcd4 by miR-21 facilitates glioblastoma proliferation in vivo. Neuro Oncol 2011;13:580-590.

-40 Chen C, Cheng G, Yang X, Li C, Shi R, Zhao N: Tanshinol suppresses endothelial cells apoptosis in mice with atherosclerosis via IncRNA TUG1 up-regulating the expression of miR-26a. Am J Transl Res 2016;8:29812991.

41 Lankat-Buttgereit B, Goke R: Programmed cell death protein 4 (pdcd4): a novel target for antineoplastic therapy? Biol Cell 2003;95:515-519.

42 Cmarik JL, Min H, Hegamyer G, Zhan S, Kulesz-Martin M, Yoshinaga H, Matsuhashi S, Colburn NH: Differentially expressed protein Pdcd4 inhibits tumor promoter-induced neoplastic transformation. Proc Natl Acad Sci U S A 1999;96:14037-14042.

43 Zhang H, Ozaki I, Mizuta T, Hamajima H, Yasutake T, Eguchi Y, Ideguchi H, Yamamoto K, Matsuhashi S: Involvement of programmed cell death 4 in transforming growth factor-beta1-induced apoptosis in human hepatocellular carcinoma. Oncogene 2006;25:6101-6112.

44 Liang X, Xu Z, Yuan M, Zhang Y, Zhao B, Wang J, Zhang A, Li G: MicroRNA-16 suppresses the activation of inflammatory macrophages in atherosclerosis by targeting PDCD4. Int J Mol Med 2016;37:967-975.

45 Seimon TA, Wang Y, Han S, Senokuchi T, Schrijvers DM, Kuriakose G, Tall AR, Tabas IA: Macrophage deficiency of p38alpha MAPK promotes apoptosis and plaque necrosis in advanced atherosclerotic lesions in mice. J Clin Invest 2009;119:886-898.

46 Chi H, Barry SP, Roth RJ, Wu JJ, Jones EA, Bennett AM, Flavell RA: Dynamic regulation of pro- and antiinflammatory cytokines by MAPK phosphatase 1 (MKP-1) in innate immune responses. Proc Natl Acad Sci U S A 2006;103:2274-2279.

47 Jiang Y, Gao Q, Wang L, Guo C, Zhu F, Wang B, Wang Q, Gao F, Chen Y, Zhang L: Deficiency of programmed cell death 4 results in increased IL-10 expression by macrophages and thereby attenuates atherosclerosis in hyperlipidemic mice. Cell Mol Immunol 2016;13:524-534. 